\title{
INTEGRATION OF 3D MODEL FROM UAV SURVEY IN BIM ENVIRONMENT
}

\author{
V. Barrile ${ }^{1}$, A. Fotia $^{1 *}$, G. Candela ${ }^{1}$, E. Bernardo $^{1}$ \\ ${ }^{1}$ Mediterranea University - Department of Civil, Energy, Environmental and Materials Engineering (DICEAM) - Via Graziella Feo \\ Di Vito Reggio Calabria Italy - (vincenzo.barrile, antonino.fotia)@unirc.it
}

Commission

KEY WORDS: UAV, HBIM, Cultural Heritage

\begin{abstract}
:
Relevant cultural heritage buildings have been subject to numerous maintenance interventions over the years. Building Information Modelling (BIM) technology is already part of the construction industry especially in the design phase and is considered as a very useful tool. From a survey with an Unmanned Aerial Vehicles (UAVs), using photogrammetry is possible to determine characteristics such as sizes and shape object, volumes, areas, distances, elevations and furthermore the reconstruction of highquality model. A whole integration between the two methods will be a "game changer" for the construction sector. Moreover, old buildings have complex architecture, with high and particular details that today's BIM software's aren't able to perfectly represent today.

In this paper, we present a methodology to integrate into BIM environment a 3D reconstruction as-built drawings of an old church using photogrammetric techniques, in order to find a solution to reproduce the complex details present in ancient buildings.
\end{abstract}

\section{INTRODUCTION}

Relevant cultural heritage buildings have been subject to numerous maintenance interventions over the years. In most cases, however, the absence of blue prints makes restoration work particularly complex. The use of the Heritage Building Information Modelling (HBIM) allows the representation of the historical building and the preparation of an updatable documentation including, in a single digital environment, not only geometrical information but also historical data.

Since the architectural cultural heritage constructions are already existing, the first acquisition phase is mandatory (through photogrammetric or laser scanner survey) in order to acquire geometrical information but also $3 \mathrm{~d}$ space to plan the restoration interventions.

However, the complex architecture of ancient buildings represents a problem that today's BIM software's have to face. Basic modelling tools and elements are essentially based on finite and mathematical systems, and as for each tool the types are multiple, in most cases they were not enough to create the necessary elements.

To overcome these critical issues the present method reports the methodology used by the authors for the realization of HBIM of the church of Sant'Antonio Abate in Reggio Calabria.

The reconstruction of BIM models of the existing structures, especially the cultural heritage sector, allows the conservation and promotion of any restoration or partial reconstruction, especially in countries such as Italy, built on seismic territory and exposed to high earthquake risks.

Even if the final restitution sufficiently reflects the objectives pursued, it should be emphasized how the realization times are not satisfactory for the optimization of the process of returning the as-built model and therefore of the subsequent design and management phases.

\section{BIM \& HBIM}

\subsection{BIM}

In recent years, we are witnessing an ever-increasing diffusion of the BIM (Building Information Modelling) methodology. Building Information Modeling is a process that is based on a construction of a model of the building as digital representation of all the information regarding its characteristics.

BIM represents a process that involves all the life phase of the structure, from development to maintenance, with the possibility to share it among the stakeholders involved in the structure life-cycle.

This type of process makes it possible to carry out complete analysis on the model, such as structural, energy, lighting, materials, acoustic allowing the possibility to simulate different scenarios, making these tools fundamental in every process.

In the BIM modeling process, the visualization of each part of the model or of any analysis that it is intended to perform, is a query that applies to the model itself; the project is unique and as such any modification made a single element is automatically propagated to the entire model, consequently modifying all the analyzes and views.

A process originally conceived for new buildings can represent a valid tool for existing buildings with the correct adaptation, especially in a historical period with particular focus on restoration. In this perspective the possibility to use the advantages of the information management guaranteed by the $\mathrm{BIM}$, also in the context of existing constructions became strategic. Moreover, the application of this digitalization process to existing structure, can facilitate the disclosure of the built heritage, improving both the methods of data acquisition and modelling process.

\footnotetext{
* Corresponding author
} 


\subsection{HBIM}

Applying BIM methodologies to existing buildings, we can manage in a coherent and coordinated way all the phases of the building life, according to a life-cycle approach.

In this context, it is essential to resort to the peculiarities of BIM also for the existing, for which the documentation of places, technologies and materials is increasingly important for the preservation of historical and cultural heritage.

Compared to the approaches and tools commonly used for the construction project from scratch, the information models of buildings already built require the definition of levels of knowledge that often cannot be quickly identified, since blueprints and reliable data are often missing.

To outline the scope of intervention of the BIM for existing building, the acronym HBIM has begun to spread. The term derives from a scientific contribution of 2009 by Prof. Murphy, whose methodology includes a technical process for geometric modelling and insert complex information. Existing buildings, regardless of their function, are detected using accurate survey instruments, so that the result of the measurements (as point cloud) is then compared to libraries of software objects that are superimposed on the cloud until the similarity is satisfactory. This process aims at abstracting the geometries to have lean models to which to associate data for documentation or for numerical simulations. HBIM therefore does not mean to apply BIM to already constructed buildings, but to apply different methodologies to obtain simplified models starting from a survey. Another approach (defined Scan-to-BIM) according to which the geometric components derived from the survey are obtained locally without resorting to libraries of objects already precompiled.

\subsection{From Scans to HBIM}

Currently starting from a point cloud, it's possible to generate an intelligent and parametric model that contains the highest possible degree of knowledge, however the process takes a long time to be completed.

Starting from the building detection the process needs to determine as much information as possible and transfer these return it to a model. This procedure may vary depending on the purpose with which the survey is carried out.

Current research is focusing on the development of standard procedures and automatic process to perform this operation faster than manual methods, avoiding loss of information and details.

Two main methods are actually are used: the first one compares the point cloud, with a database of objects already present in the libraries searching for the most similar ones, the second procedures uses the surface information (from the point clouds) to perform another type of classification.

Smart model contains within its parametric information's concerning geometry, physical properties, constituent materials. The process to switch from an existing object to an intelligent object consists in following a process where starting from data acquisition it's possible to obtain a digital model with information, and the way how they are displayed in the model depends on the use.

Therefore, it is possible to generate a congruent and coherent to realty model, where most of the information gathered up to that point is contained, as if it were a digital "catalog" that could be questioned in case of need.

\subsection{HBIM advantage and common problems}

The use of BIM for documentation and management of historical building presents different advantages: archive of historical documents, single access point for all data, support for technical analysis, support for scheduling maintenance interventions (the BIM model of a building, containing information related to the maintenance of each construction element, allows to have available a structured database to query with 'use of IT tools dedicated to facility management to strategically plan maintenance operations), promotion of cultural heritage, through the sharing of the model on the web or the realization of virtual or augmented reality applications, monitoring of degradation, simulation of response to catastrophic events (such as earthquakes) etc.

The use and application of BIM is actually limited in the field of cultural heritage and remains the prerogative of research centers and universities. The reasons for this imbalance can be traced back to the difficulties linked to the implementation of an existing BIM. Lack of shared regulation and standardized workflows, coupled with the considerable difficulties in the modeling phases and in the information's retrieval: uncertainties on construction techniques, a complex sequence of construction and reconstruction phases, presence of nonstandardized elements nor referable to libraries presets, complexity of architecture and presence and irregularities, etc.

\section{CASE OF STUDY}

\subsection{Sant'Antonio Abate Church}

The church of Sant'Antonio Abate is a testimony of medieval architecture in the municipality of Reggio Calabria. The first construction phase of the church dates to the XIII-XIV century when a three-aisled building with no transept was built, with pillars and tripartite apse. In this most ancient phase, the church is placed in the general framework of the Basilian-Norman architecture.

Over time, the church has been subject to several restoration in different times. At the beginning of the seventeenth century, the northern wall was rebuilt. Between 1628 and 1671, the arches of the central nave were closed, and the nave was turned into a sacristy. In the eighteenth century, the floor was raised, and the two crypts were covered with vaulted ceilings and niches on the walls for funeral depositions, according to a unique monastic custom in the city of Reggio Calabria.

Nowadays, the Church consists of three buildings: a nave with an almost rectangular plan, a side aisle to the sacristy and the bell tower. The façades are characterized by a simple architecture, while inside it is characterized by exposed stone walls. 


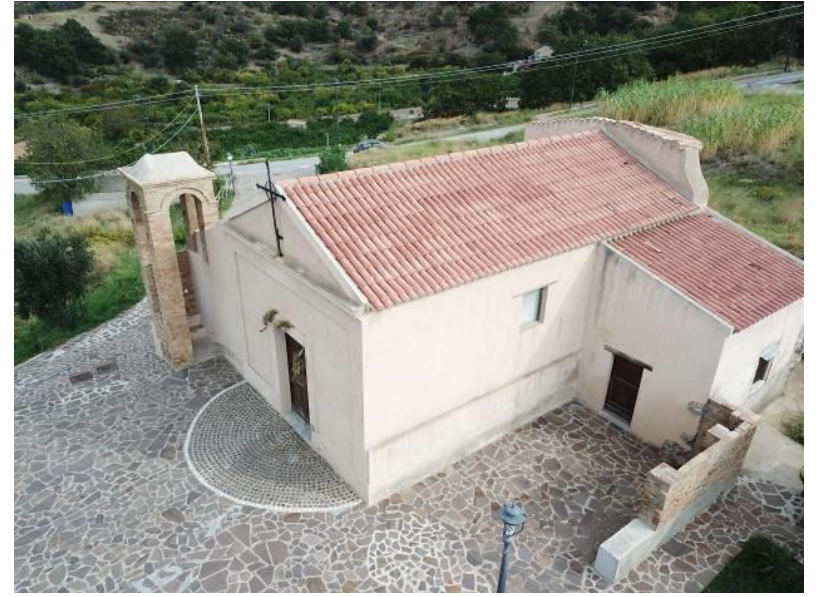

Figure 1. Sant'Antonio Abate Church

\subsection{UAV Survey}

For the acquisition phase of photographic dataset for the photogrammetric 3D reconstruction, DJI Mavic Pro (DJI; Shenzhen) UAV (Unmanned Aerial Vehicle) with CMOS $1 / 23$ " sensor was used. To obtain a model with centimetre accuracy and reconstruct an high-quality model, the image acquisition plan was divided into three steps: definition of image acquisition plan type, definition of Ground Sampling Distance (GSD), and definition of image overlap. The Image acquisition type was set to automatic waypoint flight mission so that the UAV perform an automatic flight. The software calculates the image acquisition plan and mission settings automatically, defined the following parameters: flight eight (and consequentially GSD), overlap (\%), and area to be mapped. To obtain centimetre precision $($ GSD $<1)$ at legal flight height, considering DJI Mavic Pro camera specs $(\mathrm{Sw}=$ real sensor width $=12,8333 \mathrm{~mm}, \mathrm{FR}=$ real focal length $=8.6$ $\mathrm{mm}$, imW $=$ image width pixels $5472, \mathrm{imH}=$ image height pixels 3648) maximum flight height was set to 30 meters for vertical flight. Different circular mission along the building were automatically executed using Pix 4d (Pix4d, Lausanne) flight planning software. Circular flight plan at 20, 25, and 30 $\mathrm{m}$, with camera tilt set to $70^{\circ}$ were used to gather photographic information. The acquired aerial images were integrated with additional images from the ground. The $3 \mathrm{~d}$ reconstruction was executed using Agisoft Photoscan (Agisoft, St. Petersburg) photogrammetry software. The elaboration process is composed by three different phases:

1. Photo alignment: identifying the binding points using operators of interest. The points chosen in the various photos must have characteristics in common in order to be adequately superimposed. For a good result, the quality of the image must be high; you must have few areas of shade and adequate lighting;

2. Build dense cloud. Through this phase, a dense cloud is constructed using dense image matching algorithms. These are subdivided into algorithms that use a stereo pair to find matches (stereo matching) and those that identify them in multiple images (stereo multi-view);

3. Build mesh, which consists in generating a polygonal model based on the newly created dense cloud. The mesh is a subdivision of a solid into smaller solids of a polyhedral shape; 4. Build texture, instead allows obtaining the 3D representation of the work under investigation. The obtained $3 \mathrm{~d}$ model is represented in fig. 2 and 3.

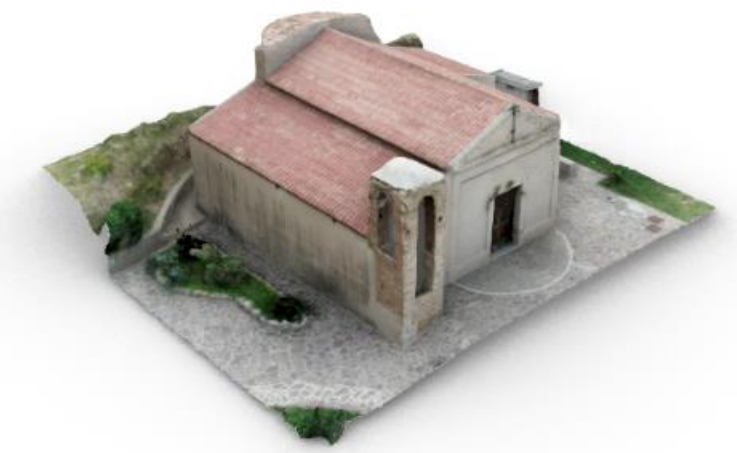

Figure 2. Perspective view of the reconstructed 3D Modeloutside

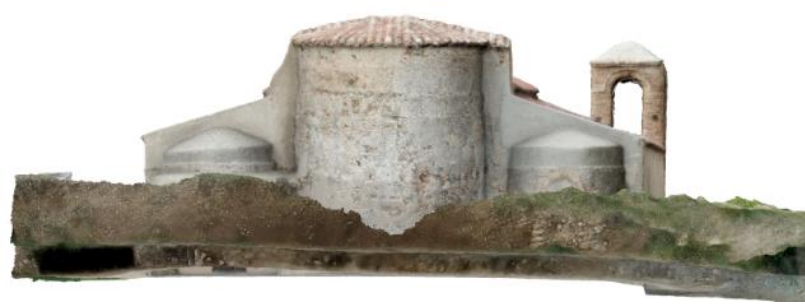

Figure 3. South view of the reconstructed 3D Model - outside

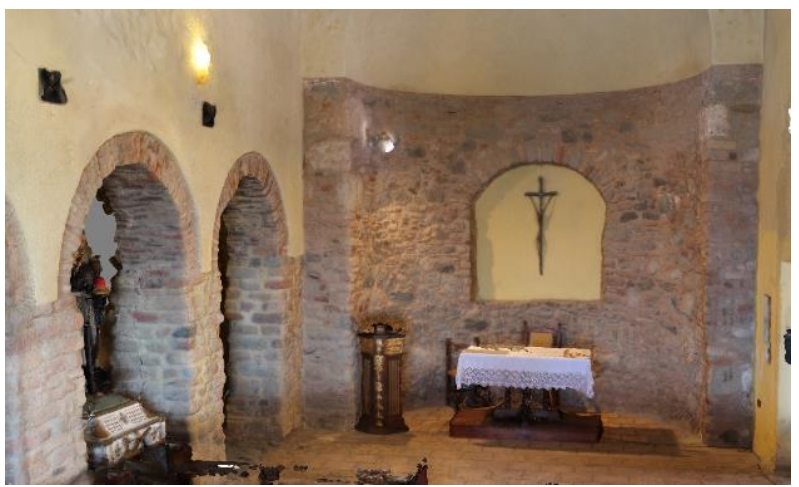

Figure 4. 3D Model - inside

The workflow followed to generate the parametric model of the church started from the digital photogrammetric survey of the building, then the already described process for the generation of the $3 \mathrm{~d}$ point clouds and related texturized meshes were executed. This procedure was also replicated inside the building. The two obtained point clouds (internal and external) were then combined with the $3 \mathrm{~d}$ software Photoscan using common key points reported on both point clouds (i.e. main entrance, pavement, wall). Then, the complete mesh model inside and outside of the church has been elaborated and a complete 3D model (mesh and texture) was realized. The obtained 3D model although excellent in geometrical terms, did not guarantee the possibility to manage each element separately. 


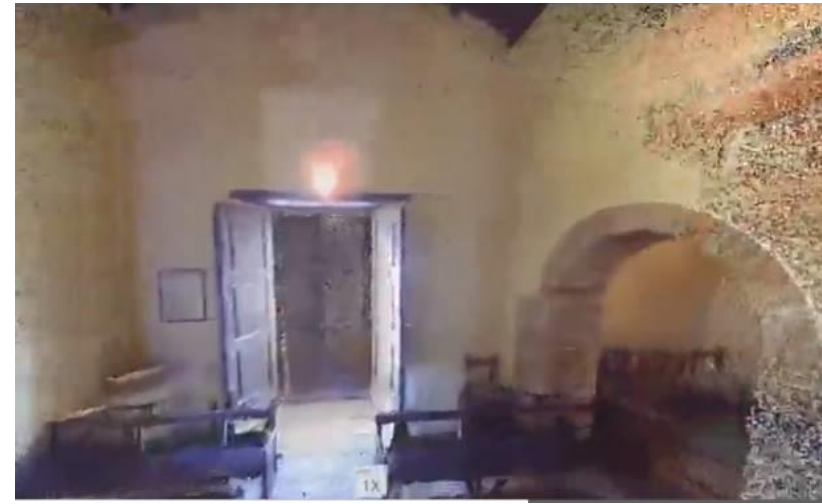

Figure 5. Sant'Antonio Abate Church - Union of clouds

\subsection{HBIM recostruction}

A reverse engineering process on the existing building was applied with the HBIM, because modelling the buildings, in the most likely way possible, need the knowledge of its characteristics, geometric, materials, historical, etc.,.

In BIM methodology, the exchange of data (between the various subjects) is essential. This information transfer is facilitated by the open IFC format (Industry Foundation Classes), which has become an international reference standard. The presence of defects and diversity in the forms makes a historic building unique.

In this regard, the methodology we followed for the realization of this model is no longer based on point clouds but on the 3D model. The 3D model was cutted in several elements to import these elements as individual elements in the BIM software (Autodesk Revit) as IFC file, using the entire cloud as a guideline for the placement of the various objects.

This process guarantee to obtain the appearance geometric and material closer to the real conformation of each component (ensuring also an information management).

In relation to the insertion of the data flow (that from different sources must flow into the model and become an integral part of the model), we proceeded by adding to the geometry technical information, description of the materials, historical information, cadastral data, presence of constraints, interventions maintenance.

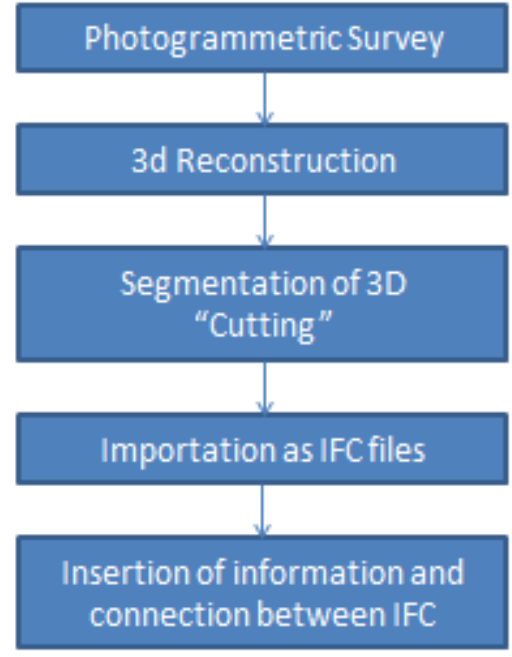

Figure 6. Reconstruction of Building Information Model

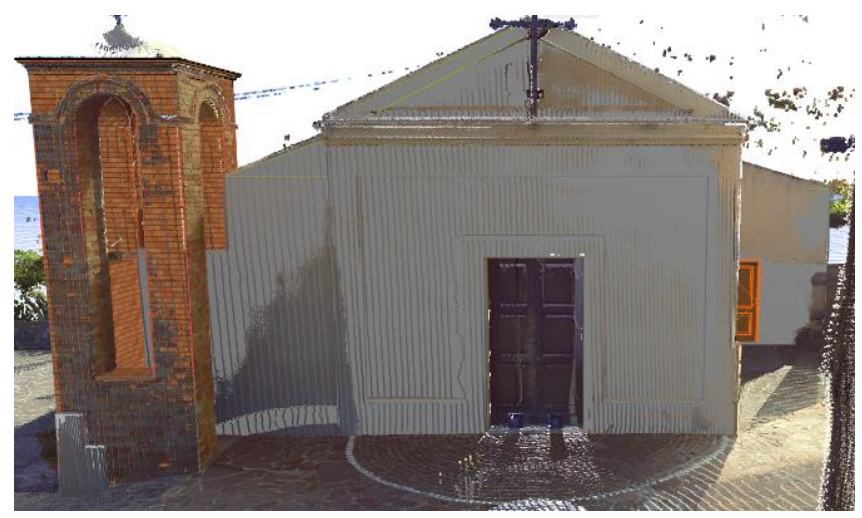

Figure 7. overlap between BIM and Dense Cloud

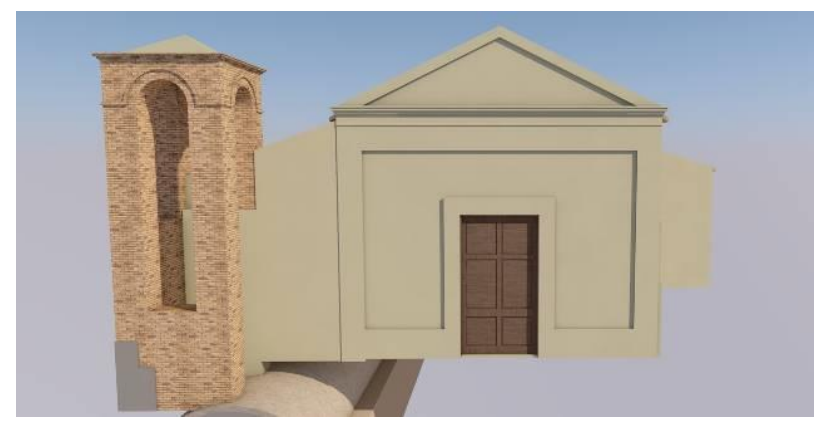

Figure 8. Reconstruction of Building Information Model

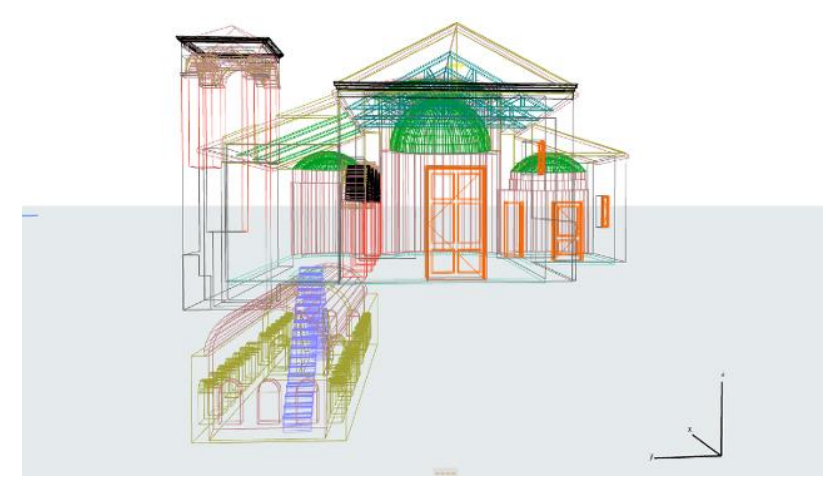

Figure 9. Reconstruction of Building Information Model

\section{DISCUSSION AND CONCLUSION}

\subsection{Discussion}

In recent years, various software has been developed to view BIM files with IFC extension. Most of these IFC Viewers offer the ability to control BIM models through classic threedimensional navigation functions.

At the same time they present many other options such as the possibility of sectioning the building project in real time, the shifting of the various floors along the axes (a kind of building assembly plan) and also other features such as lighting and switching off the various objects that make up the structure. 
From a metric point of view, using the point cloud as a reference for the insertion of the various models (IFC files), there is no metric deviation between the final model and the same point cloud. However the process to create the model, regarding time and labour applied, need other considerations: vertical and horizontal elements reconstruction process it's not time consuming and labour-intensive, but elements that have more complicated geometries need complex and manual operation.

\subsection{Conclusion}

The BIM is a process that leads to the creation and management, in all its parts, of a model of a digitally represented construction project, where all the information regarding its characteristics is contained. It is well suited to the modeling of point clouds generated by geomatics procedures such as, for example, photogrammetry from UAVs. Today the process is a key method for safeguarding the existing cultural heritage. The reconstruction of BIM models of existing structures, especially in the field of cultural heritage, allows the creation of databases that, if implemented and updated, can allow their preservation and favor the eventual restoration or partial reconstruction, especially in countries such as Italy affected by strong seismic events. However, nowadays commercial BIM software's are not designed and suited for the modeling of existing structures, so in reporting any surfaces with complex construction details they cannot be faithfully reported in the software. The same provides for the correction and the alignment of the points considered as errors. At the same time the creation of a parametric object to insert in a single class, is a way to be generic and lose information that make the historical building unique (for example different designs of the capitals of the columns of the same architectural style). In this context the results obtained in the present case study present some differences with respect to reality.

\section{REFERENCES}

Bae H, Golparvar-Fard M, White J (2013) High-precision vision-based mobile augmented reality system for contextaware architectural, engineering, construction and facility management (AEC/FM) applications. Visual. Eng. 1(1):1-13

Barrile V., Fotia A., Bilotta G., Geomatics and augmented reality experiments for the cultural heritage in Applied Geomatics Vol. 10, Issue 4, pp. 569-578 (2018)

Barrile, V., Fotia, A., Bilotta, G., \& De Carlo, D. 2019 Jan 28. Integration of geomatics methodologies and creation of a cultural heritage app using augmented reality. Virtual Archaeology Review. [Online] 10:20

D'Andria, F. (2013). Il Ploutonion a Hierapolis di Frigia. Istanbuler Mitteilungen, 63, 157-217. D’Andria, F. (2015). Terme Chiesa. In G. Scardozzi (Ed.), Nuovo atlante di Hierapolis di Frigia, Hierapolis di frigia VII, Istanbul: Yayinlari.

Dore, C., Murphy, M., 2015. Historic Building Information Modeling (HBIM). In: Brusaporci, S., Handbook of Research on Emerging Digital Tools for Architectural Surveying, Modeling, and Representation. IGI Globa, pp. 239-279.
López, F., Lerones, P., Llamas, J., Gómez-García-Bermejo, J., Zalama, E., 2018. A Review of Heritage Building Information Modeling (H-BIM). In: Multimodal Technologies and Interaction, Vol, 2(21), pp. 1-29.

Micheletti, N., Chandler, J.H. and Lane, S.N. 2015, Structure from motion (SFM) photogrammetry. Geomorphological Techniques, , 2047-0371.

Murphy, M., McGovern, E., Pavia, S., 2009. Historic building information modelling (HBIM). In: Structural Survey. Vol. 27, pp. 311-327.

Nardi, G., 2001. Tecnologie dell'architettura Teorie e Storia. Libreria CLUP. Odorizzi, P., 2017. L'approccio digitale nei progetti e nelle costruzioni. Costruzioni Metalliche, Vol. 64 (6), pp. 9-12.

Paris, L., Wahbeh, W., 2016. Survey and representation of the parametric geometries in HBIM. In: Disegnarecon, Vol. 9(16), pp. 12.1-12.9.

Piras, M., Di Pietra, V., \& Visintini, D. (2017). 3D modeling of industrial heritage building using COTs system : test, limits and performances. International Archives of the Photogrammetry, Remote Sensing and Spatial Information Sciences, XLII-2/W6, 281-288. doi:10.5194/isprs-archives-XLII-2-W6-281-2017

Pocobelli, D.P., Boehm, J., Bryan, P., Still, J., Grau-Bové, J., 2018. BIM for heritage science: a review. In: Heritage Science, Vol. 6 (30), pp. 1-15.

Ronchetta, D. (2015). Necropoli Nord. In: Scardozzi (Ed), Nuovo atlante di Hierapolis di Frigia, Hierapolis di Frigia VII. Istanbul: Yayinlari. uav photogrammetry for archaeological site survey. $3 \mathrm{~d}$ models at the hierapolis in phrygia (turkey) Virtual Archaeology Review, 9(18): 28-43, 201843

Rinaudo F, Bornaz L, Ardissone P, 2007 3D high accuracy survey and modelling for Cultural Heritage Documentation and Restoration. Vast 2007-future technologies to empower heritage professionals, November 26-29, 2007, Brighton, UK, Archaeolingua Hun, pp. 19-23

Ruiz Sabina, J., Gallego Valle, D., Peña Ruiz, C., Molero García, J., \& Gómez Laguna, A. (2015). Aerial photogrammetry by drone in archaeological sites with large structures. Methodological approach and practical application in the medieval castles of Campo de Montiel. Virtual Archaeology Review, 6(13), 5-19. doi:10.4995/var.2015.4366

Semeraro, G. (2016), Ricerche nel Santuario di Apollo (20072011). In F. D'Andria, M. P. Caggia \& T. Ismaelli (Eds.), Hierapolis Di Frigia VIII, Le Attività delle Campagne di Scavo Restauro 2007-2011. Istanbul: Yayinlari.

Volk, R., Stengel, J., Schultmann, F., 2014. Building Information Modeling (BIM) for existing buildings Literature review and future needs. Autom. Constr. Vol. 38, pp. 109-127. https://doi.org/10.1016/j.autcon.2013.10.023 173-181. 